\title{
Third-party Governance Contract System of Rural Environmental Pollution
}

\author{
Xianhua $\mathrm{Wu}^{1}$, Yadong $\mathrm{Xue}^{2}$, Hong Chen ${ }^{1}$ \\ ${ }^{1}$ Yuxi Research Center for Eco- environmental Sciences on Plateau Lakes, Yuxi Normal University, \\ Yuxi Yunnan, 653100, China \\ ${ }^{2}$ Yuxi Center for Disease Control and Prevention, Yuxi Yunnan, 653100, China
}

Key words: Rural environmental pollution, Third-party governance, Contract system.

\begin{abstract}
With continuous economic development and social progress, more and more environmental problems (especially the problem of rural environmental pollution) emerge. The solution to rural environmental pollution cannot be separated from third-party governance. This requires certain contract system. It can effectively solve such problems as unsound legal governance of environmental problems, non-perfect capital and technology and unsound management system which are caused by insufficient governance force. Contract system is an effective way to solve such problems. In rural area, annual gain of rural environmental governance, agriculture degree and performance evaluation may serve as the conditions for third-party contact in rural environmental pollution governance. In this aspect, China still needs to refer to foreign environmental management mode. Western management effect is most effective. Thus, the government may authorize environmental pollution governance to rural grass-roots organizations, and let them manage environment in accordance with China's constitution and listen to the opinions of the public so as to make contributions to establishing better rural environmental pollution governance system.
\end{abstract}

\section{Introduction}

The improvement of third-party contract system for rural environmental pollution governance is the fundamental guarantee to solve rural environmental pollution. Although the governance system as the core content of improving rural environmental pollution improves environmental pollution problem to certain degree, some problems also appear in system implementation process. Thus, it is required to solve these problems by all means. To solve these problems, six aspects are required to ensure all-round governance of rural environmental pollution, including multi-party negotiation, legislative guarantee, supervision, contract generation, interest driving and final responsibility investigation. Third-party governance of environmental pollution was first proposed on the Third Plenary Session of the $18^{\text {th }}$ Central Committee of CPC. Then, various places implemented it. Hence, we carry out analysis and discussion of third-party contract for rural environmental pollution governance.

\section{Feasibility and necessity of rural environmental pollution governance}

\section{Feasibility analysis}

Firstly, China has implemented third-party governance system for rural environmental pollution. The amount of agricultural commercialization complies with the requirements of third-party governance. In rural area, third-party governance of industrial and mineral industrial pollution is same. Thus, the feasibility depends on the degree of agricultural commercialization. All decentralized contractors may be deemed as enterprise customers, so the trading cost will rise. In 2014, General Office of the CPC Central Committee and General Office of the State Council printed and issued Opinions on 
Guiding Orderly Transfer of Rural Land Management Right and Developing Moderate Scale Management of Agriculture. At the end of 2014, the number of operation households with the management area of at least 50mu had exceeded 3 million; cooperatives of agriculture and animal husbandry had been nearly 900,000; there had been 1.3 million of cooperatives. The above data basically prove rural commercialization degree follows the conditions of third-party governance. Secondly, the gain of rural environmental pollution governance is much higher than that of urban environmental pollution governance. The basic power of governance depends on governance gain. For third-party enterprises, rural industry is higher than urban industry in other aspects, except the gain. (1) waste water treatment and daily household refuse treatment at suburbs may be carried out with some urban treatment methods. Then, waste water is treatment with some low-cost methods such as physical method and biological method. (2) chemical fertilizers and pesticides may be treated with technical guidance and supervision. (3) The investment of third-party governance enterprises in rural area. To invest less and profit a lot, the third-party enterprises may gain profits through derivative projects. For rural area, domestic pollution treatment and treatment of industrial and mineral industrial pollution directly influence governance gain and concern many aspects. It is very important to solve practical problems. In terms of third-party governance, the wastes may be recycled. Besides, organic green food and certified pollution-free food may be applied for to the state so as to achieve product value gain. Therefore, it is required to increase the gain of third-party governance of rural environmental pollution and make is more feasible.

Finally, feasibility estimation may be implemented for the performance of rural environmental pollution. It as an important basis for governance performance evaluation is closely related to third-party governance of rural environmental pollution.

\section{Necessity analysis}

Due to the influence of city-countryside dual system, China firstly tilts to cities in terms of capital input problem, legislation resource problem and organizational procedure. Thus, technical shortage, unsound legal system for governance and the lack of subject status are caused. Based on current situation, almost nobody manages and governs these aspects in rural area so that rural waste water discharge method is incorrect. In addition, treatment rate of waste water is only $10 \%$, and the treatment rate of daily household refuse is less than $40 \%$. Rural heavy pollution discharge increases every day. It thus can be seen that the introduction of third-party governance mode can basically solve the above problems and play a great role for future rural environmental management.

Firstly, third-party management can offer technical and capital support for rural environmental governance and problem solution. In accordance with the legal system formulated in 2014, total investment amount of environmental infrastructure for city environment is nearly 960 billion. Three simultaneous projects and industrial pollution governance interact. In rural aspect, the funds provided by the government are insufficient for a long term, because initial investment in rural environmental protection plan is low. Thus, the rural area can solve the problem only through third-party environmental protection. Meanwhile, this can promote capital input in rural environmental governance for third parties and enhance rural economic circulation, production cleanness and green ecological technology of agriculture. Secondly, the introduction of third-party contract for rural environment governance can make up for unsound legal system. In Chinese rural area, environmental protection laws are decentralized in the laws oriented to urban and industrial environmental protection. Timeliness and hysteresis nature of legislation still exist. Rural third-party governance contract can govern the specific situations of government subject so that announcements which are not legislated in time and needed urgently can be fully and rationally placed in the contract. This not just effectively solves post-legislation problems and legislation delay problem, but also solves some obligations and contract rights as per relevant laws. This mode shows strong operability. It can fully and effectively enhance timeliness of rural environmental protection law, so it is necessary. Finally, to form the situation of multi-party governance of rural environment, third-party governance must be introduced. Comprehensive Assessment Technology Guide for Rural Environment Quality issued by 
the environmental protection sector indicates that most rural monitoring systems are still in the initial stage. For various reasons, rural environmental pollution treatment has not been managed well by households, rural economic subjects and village committees. Due to the lack of government control, environmental protection is not ideal. Third parties may be introduced for management to form multi-party governance situation.

\section{Third-party governance contract subject of rural environmental pollution}

The state defines the third-party governance of environmental pollution as follows, "pollution removers entrust environmental service companies to treat pollution through paying certain expenses as stipulated in the contract". The development tendency of environmental monitoring reform is inevitable. Rural environmental pollution is serious. Only regional governance can bring good effect. To achieve this, government bid invitation is required. Most village committees sign rural pollution governance responsibility letter with the government to expand governance of rural environment and enhance the third-party responsibility. In this way, the third party may implement environmental governance with the assistance of village committees. Thus, third-party governance of rural environment means the government can well specify the governance responsibility and apply bidding mode to entrust regional rural environment governance to a third party. Then, the government may implement monitoring and evaluation of governance performance.

Firstly, contract sovereignty of the government is hold by the town government. To govern rural environment on a large scale, taking the county as the unit is not very good, because the region is too large. Thus, the town may be adopted as the unit for management, supervision and investigation. Rural management involves too many aspects, such as environmental protection, forestry, agriculture and animal husbandry. Thus, single sector should not sign, but the town government should sign. Secondly, rural contract subjects include agricultural enterprises, village industrial and mining enterprises, village economic organizations and village committees. The town government should sign the responsibility letter with the village committee to monitor the environment and assist the third party in treating environment and rural environmental pollution etc. But pollution governance is independent management of rural economic entity. Other representatives have no right to amend the contract and can only play the role of mobilization. Finally, after third-party governance enterprise signs the contract with the town government, it still needs to negotiate with agricultural enterprises. In the process of environmental governance, third-party governance system acts as the role of advanced technology promoter. Different from pollution governor, it pays more attention to generalizing ecological agriculture to rural area, such as water saving, soil measurement, fertilization, insect resistant, favorable sowing and other technologies. It applies for product agency to the relevant economic subject of agent village and carry out certification tracking for agricultural products so as to make the products appreciate.

\section{Type of third-party governance contracts for rural environmental pollution}

In the third-party governance of rural environmental pollution, government and village contract serve as the subjects, and third-party governance enterprises and environment monitoring institution sign the administrative contracts and civil contracts. Administrative contracts include three types: rural environmental governance contract, rural environmental governance responsibility letter, and rural environment monitoring commission contract. Civil contracts include five types: rural soil restoration agreement, clean production service agreement of agricultural enterprises, commission governance agreement of rural domestic pollution, clean production service agreement of contractors, and clean production service agreement of rural industry and mineral industry.

Administrative contracts refer to maintenance of administrative institutions and public benefit promotion to reach a consensus in order to achieve management objective. Administrative contracts of rural third-party governance can change the contract rights for beneficial policy so as to motivate governance enthusiasm. Applicative sanction for the breach of contract may be applied beyond the 
scope of legal liability investigation to handle those legal sanction cannot handle. Besides, performance appraisal, reward and punishment may be detailed to effectively motivate and promote the governance subjects.

The civil contract is the contract signed between the third-party governance enterprise and village economic entity. It will connect each party of the contract through governance gain and achieve "beautiful village" building through cooperation, mutual benefit and win-win. Firstly, commission right agreement of rural domestic pollution government. At present, many regions have carried out third-party governance. Regardless of economy, each place has corresponding measures and methods. Secondly, cleanness of agricultural enterprises and corresponding production service agreements. Thirdly, clean production service agreement of contractors. Fourthly, clean production service agreement of rural industry and mineral industry as well as final rural soil restoration agreement etc.

\section{Conclusions}

This paper analyzes and discusses third-party governance contract system for rural environmental pollution, fully studies future governance mode, eliminates various difficult factors and achieves optimal treatment of basic problems. The third-party governance contract system conforms to China's strategy of sustainable development. On this basis, the author hopes relevant personnel can continue to study and think over relevant problems so as to provide more reliable and efficient policies and measures for establishment of third-party governance contract system for rural environmental pollution in order to solve rural environmental protection issue, make due contributions to future embroilment and offer guarantee for people's life.

\section{Acknowledgement}

Fund project: subsidized by the support plan of scientific and technological innovation team of Yunnan colleges (IRTSTYN201422).

\section{References}

[1] Wu Weiyu, Xiao Ping, Contract Management: Effective Mode of Rural Environment Governance in China, Legislation Research Center, Law School of Nanchang University, 2015(4).

[2] Xiao Ping, Zhu Guohua, Contract System for Rural Non-point Source Pollution Governance, Legislation Research Center, Law School of Nanchang University, 2015(12).

[3] Xiao Ping, Zhu Guohua, Selection of Rural Environmental Pollution Governance Mode and Governance System Construction, Legislation Research Center, Law School of Nanchang University, 2014(7).

[4] Xiao Ping, Zhu Guohua, Study on Third-party Governance Contract for Rural Environmental Pollution, Legislation Research Center, Law School of Nanchang University, 2016(4).

[5] Teng Yanjuan, Third Party Legal Status of Environmental Pollution Governance, Law School of Renmin University of China, 2015(4).

[6] Liu Chang, On the Real Obstacle and its Resolve Mechanism of Environmental Pollution's Third Party Management, Law School of Daliann Maritime University, 2016(3).

[7] Li Xuesong, Wu Ping, Cao Wanying, Risk Analysis and System Safeguard of Third-party Governance of Environmental Ppollution, Associate professor of Economics and management School of Wuhan University, graduate student of Economics and management School of Wuhan University, graduate student of Economics and management School of Wuhan University, 2016 (2). 
[8] Liu Junmin, Li mengjiao, Environmental Pollution by a Third Party Legal Difficulties and Cracking, 2016(4).

[9] Wang Libin, Experience of First Issuance of Concept of "Three-power Separation" of Rural Land, Chinese Journalist, 2015(6).

[10]Wang Erde, The state will standardize third-party governance of environmental pollution and promote the government to pursue environmental monitoring service from the society, Financial Report of the 21st Century, 2014(11).

[11]Cai Changqing, Contract Management of Village Affairs: Great Innovation of Chinese Village Governance mode - Case Study of Contract Management of Village Affairs of Ar Horqin Banner, Southern Forum, 2010 (1). 